\title{
Analysis and calculation of normal section of reinforced concrete beam under non-limit state
}

\author{
Jinsheng Han ${ }^{1}$, Chuanfang Guo ${ }^{1, *}$, Hong Zhang ${ }^{1}$
}

${ }^{1}$ Key Laboratory of Disaster Prevention and Reduction of Civil Engineering in Shandong Province,School of Civil Engineering and Architecture, Shandong University of Science and Technology, Qingdao, Shandong, 266590, China.

\begin{abstract}
The force analysis of reinforced concrete flexural members are usually focused on the limit state that the strain at the edge of the compressive zone of concrete reaches its ultimate compressive strain. However, it is necessary to analyze and calculate the force and deformation under non-limit state in many case. In this paper, the flexural and deformation properties of reinforced concrete beam under non-limit state were studied. Firstly, a program was compiled to analyze the stress distribution in the compression zone of concrete under non-ultimate state, and the stress graph was equivalent to a rectangular stress graph. The numerical results of the stress equivalent coefficient and the height equivalent coefficient of the compression zone were obtained, and the variation curve of the equivalent coefficient was drawn. Secondly, the practical calculation formulas were proposed to calculate the equivalent coefficient of the compression concrete zone under non-limit state by curve fitting. Then, the calculation method of reinforced concrete flexural beams under non-limit state was analyzed by the equivalent coefficient formulas. Finally,a calculation example of flexural bearing capacity of reinforced concrete beams under non-limit state was given.
\end{abstract}

\section{Introduction}

The "Code for design of concrete structures" ${ }^{[1]}$ gives values for various concrete equivalent coefficient with different grades including in $\alpha_{1}$ and $\beta_{1}$. However, this equivalence is only applicable to the limiting state of compressive strain at the edge of concrete in the compression zone. When the reinforced concrete beam does not reach the limit state, the section load analysis cannot be performed using the fixed conversion factor given in the code.

Up to now, there have been a lot of researches on the whole process of stress and deformation of reinforced concrete beams. Among them, Reference [2] studied the influence of secondary loading on the ultimate bearing capacity of beams. Some references had studied the influence of the initial strain on the ultimate bearing capacity of the beam ${ }^{[3]}$, the influencing factors of the lagging strain ${ }^{[4]}$, the lagging strain effect ${ }^{[5]}$ and the calculation formula of the lagging strain ${ }^{[6]}$. Reference [7] considered different failure modes, and obtained the formula for calculating the bearing capacity of a normal section of reinforced concrete beams. Similar studies involved forcing analysis under non-limit state. Therefore, it is necessary to strengthen the research in this field and give practical analytical methods.

In this paper, the stress distribution in the concrete compression zone under non-limit state was simulated numerically based on a plane cross-section assumption and the conclusion that the tension zone will quit after cracking. The law of equivalent coefficient of stress distribution in the compression zone was analyzed. And the practical calculation method of equivalent coefficient under non-limit state was given. Moreover, the calculation method of section force of reinforced concrete beam under non-limit state was also analyzed. The corresponding calculation formula and several calculation examples under non-limit state were demonstrated.

\section{Numerical simulation of the stress in the concrete compression zone under non-limiting conditions}

\subsection{Stress analysis of the concrete compression zone under non-limit state}

As shown in Fig.1(a), it is assumed that the compressive strain in the edge of the concrete compression zone was an arbitrary value $\varepsilon_{\mathrm{c}}$ and the actual compression zone height was $x_{\mathrm{n}}$.The strain of any point in the compression zone can be determined based on the flat section assumption, The stress-strain relationship of concrete was adopted according to equation (1) ${ }^{[1]}$. The stress distribution in the compression zone is shown in Fig.1(b).

"Corresponding author:gcf941204@163.com 


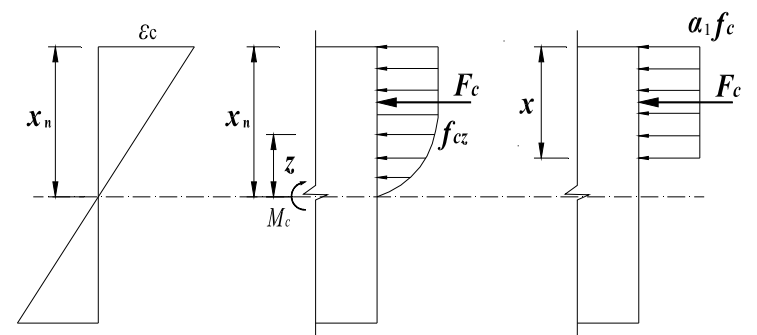

(a)Section strain (b)Section stress (c)Equivalent section stress

Fig.1. Stress analysis of the concrete compression zone under non-limit state

$$
\begin{gathered}
\sigma_{\mathrm{c}}=\left\{\begin{array}{cc}
f_{\mathrm{c}}\left[1-\left(1-\frac{\varepsilon_{\mathrm{c}}}{\varepsilon_{0}}\right)^{n}\right] & \varepsilon_{\mathrm{c}} \leq \varepsilon_{0} \\
f_{\mathrm{c}} & \varepsilon_{\mathrm{c}}>\varepsilon_{0}
\end{array}\right\} \\
n=2-\frac{1}{60}\left(f_{\mathrm{cu}, \mathrm{k}}-50\right) \\
\varepsilon_{0}=0.002+0.5\left(f_{\mathrm{cu}, \mathrm{k}}-50\right) \times 10^{-5} \\
\varepsilon_{\mathrm{cu}}=0.0033-\left(f_{\mathrm{cu}, \mathrm{k}}-50\right) \times 10^{-5}
\end{gathered}
$$

According to the stress distribution in the compression zone, the resultant force $F_{\mathrm{c}}$ of the stress and its moment $M_{\mathrm{c}}$ about the neutral axis can be integrated. Then the stress graph can be equivalent to a rectangular stress graph, and the stress equivalence coefficient and the height equivalence coefficient of the compression zone can be obtained.As shown in Fig.1(c) and equations (2) - (3), the principles of equivalence are the resultant force and the resultant acting point of the actual stress graph, which is the same as the resultant force and the resultant point of the equivalent rectangular stress graph. The product of the equivalent coefficient $\alpha_{1} \beta_{1}$ is convenient for solving the resultant force of the concrete compression zone, as shown in equation (4). The equivalent coefficient $\beta_{1}$ can be used to determine the position of the combined force in the compression zone, as shown in equation (5).

$$
\begin{gathered}
F_{\mathrm{c}}=\int_{0}^{x_{\mathrm{n}}} f_{\mathrm{cz}} b \mathrm{~d} z=\alpha_{1} f_{\mathrm{c}} \cdot \beta_{1} x_{\mathrm{n}} \cdot b=\alpha_{1} \beta_{1} \times f_{\mathrm{c}} b x_{\mathrm{n}} \\
M_{\mathrm{c}}=F_{\mathrm{c}}\left(x_{\mathrm{n}}-x / 2\right) \\
\alpha_{1} \beta_{1}=F_{\mathrm{c}} /\left(f_{\mathrm{c}} b x_{\mathrm{n}}\right) \\
\beta_{1}=2\left(x_{\mathrm{n}}-M_{\mathrm{c}} / F_{\mathrm{c}}\right) / x_{\mathrm{n}}
\end{gathered}
$$

\subsection{Numerical analysis procedures}

In this paper, a numerical simulation program was compiled. In the process of increasing the concrete compressive strain, the strain, stress, resultant force and equivalent coefficient of the concrete compressive zone were calculated in layers. The analysis results were output. The flow chart of the program simulation calculation is shown in Fig. 2.

\subsection{Equivalent coefficient curves}

The variation curves of equivalent coefficients of each grade of concrete $\alpha_{1} \beta_{1}$ and $\beta_{1}$ obtained by numerical simulation are shown in Fig.3. It can be seen that with the increase of ratio of compressive strain to ultimate compressive strain of concrete edge $\varepsilon_{\mathrm{c}} / \varepsilon_{\mathrm{cu}}$, the product of the equivalent coefficient $\alpha_{1} \beta_{1}$ increased approximately in a parabola form, with a faster increase at the beginning and a slower increase at the later stage. The magnitude of the increase of the equivalent coefficient $\beta_{1}$ was relatively small, and the speed of the increase gradually increases slightly. With the increase of the concrete strength grade, the values of the equivalent coefficients $\alpha_{1} \beta_{1}$ and $\beta_{1}$ both decreased, but the change trends were consistent.

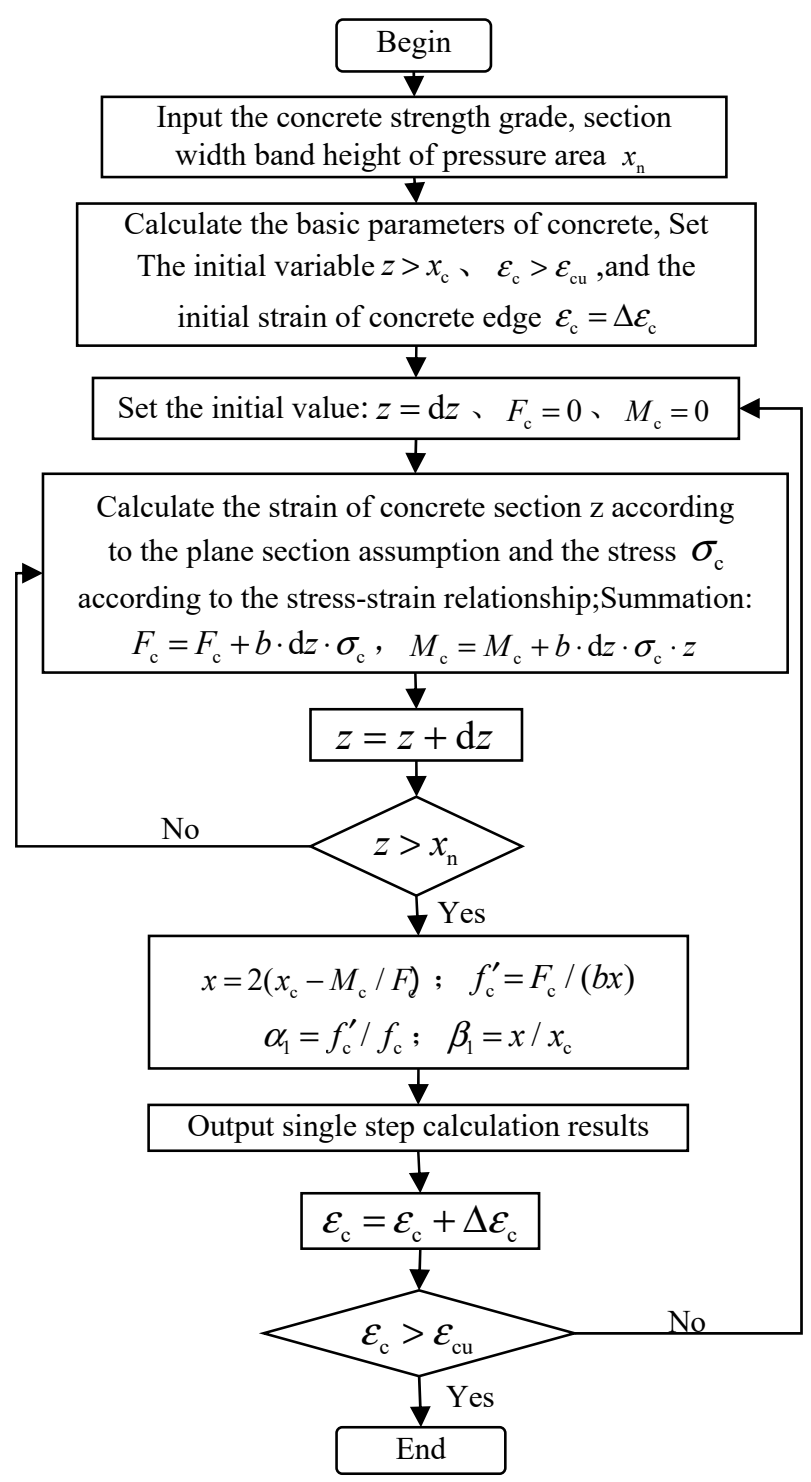

Fig.2. Numerical simulation program flow chart

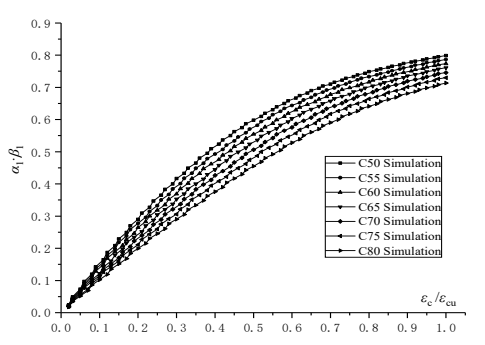

(a) Numerical simulation results of $\alpha_{1} \beta_{1}$ 


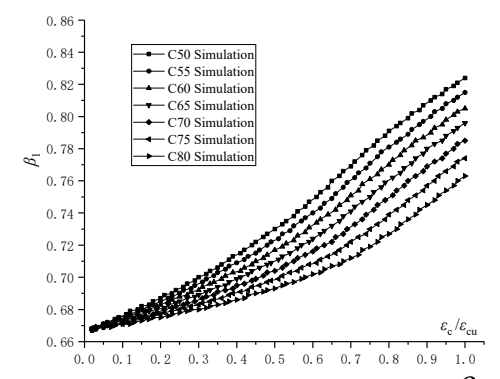

(b) Numerical simulation results of $\beta_{1}$

Fig.3. Numerical simulation results of the equivalent coefficient

\section{The equivalent force coefficients of compressive region concrete under non-limit state}

It can be seen from Fig.3, the equivalent coefficient curves of different concrete strength levels were basicallevenly spaced. From the curves of C50 and C80 concrete, the curves of other grades in concrete can be acquired. Because higher-order functions are difficult to calculate by hand, a three-stage linear equation was used for fitting, and the fitting results are shown in Fig.4.The strategic point coordinates of other strength grade concrete can be obtained by linear limiting of strength grade. Equation (6) - (8) are the fitting equation after finishing. The values of parameters in the formula are given in Table 1.

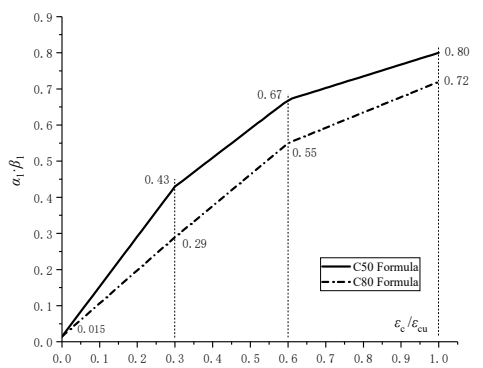

(a) Fitting curve of $\alpha_{1} \beta_{1}$

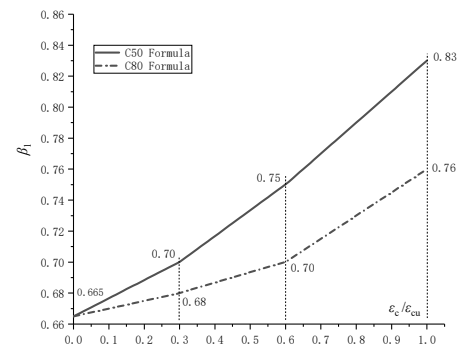

(b) Fitting curve of $\beta_{1}$

Fig.4. Fit curve of the equivalent coefficient

$$
\begin{gathered}
\alpha_{1} \cdot \beta_{1}=\xi_{1}+\xi_{2} \frac{\varepsilon_{\mathrm{c}}}{\varepsilon_{\mathrm{cu}}} \\
\beta_{1}=\eta_{1}+\eta_{2} \frac{\varepsilon_{\mathrm{c}}}{\varepsilon_{\mathrm{cu}}} \\
\alpha_{1}=\zeta_{1}+\zeta_{2} \frac{\varepsilon_{\mathrm{c}}}{\varepsilon_{\mathrm{cu}}}
\end{gathered}
$$

\begin{tabular}{|c|c|c|c|c|c|c|c|c|c|c|c|c|c|}
\hline \multirow{2}{*}{\multicolumn{2}{|c|}{$\begin{array}{c}\text { Concrete } \\
\text { strain level } \\
\varepsilon_{c} / \varepsilon_{c u}\end{array}$}} & \multicolumn{2}{|c|}{$\xi_{1}$} & \multicolumn{2}{|c|}{$\xi_{2}$} & \multicolumn{2}{|c|}{$\eta_{1}$} & \multicolumn{2}{|c|}{$\eta_{2}$} & \multicolumn{2}{|c|}{$\zeta_{1}$} & \multicolumn{2}{|c|}{$\zeta_{2}$} \\
\hline & & $\leq \mathrm{C} 50$ & $\mathrm{C} 80$ & $\leq \mathrm{C} 50$ & $\mathrm{C} 80$ & $\leq \mathrm{C} 50$ & $\mathrm{C} 80$ & $\leq \mathrm{C} 50$ & $\mathrm{C} 80$ & $\leq \mathrm{C} 50$ & $\mathrm{C} 80$ & $\leq \mathrm{C} 50$ & $\mathrm{C} 80$ \\
\hline I & $\leq 0.3$ & 0.015 & 0.015 & 1.382 & 0.916 & 0.665 & 0.665 & 0.117 & 0.050 & 0 & 2.033 & 0 & 1.467 \\
\hline II & $\leq 0.6$ & 0.190 & 0.030 & 0.799 & 0.866 & 0.650 & 0.660 & 0.167 & 0.067 & 0.320 & 0.967 & 0.100 & 1.133 \\
\hline III & $\leq 1.0$ & 0.475 & 0.295 & 0.325 & 0.425 & 0.630 & 0.610 & 0.200 & 0.150 & 0.795 & 0.175 & 0.540 & 0.400 \\
\hline
\end{tabular}

Table 1. Calculation parameters of the equivalent coefficient

The comparison between the calculation results form the linear fitting formula given in equation (6) and equation (7) and the numerical simulation results are shown in Fig. 5. Fitting accuracy was relatively ideal and fully meet the engineering accuracy requirements.

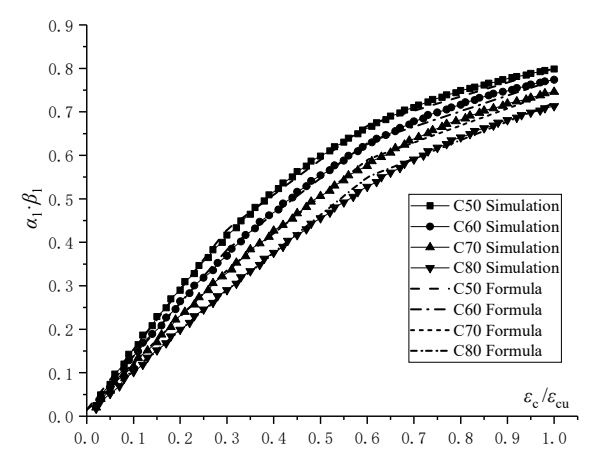

(a) Comparison of the calculation results of $\alpha_{1} \beta_{1}$ and the numerical fitting results

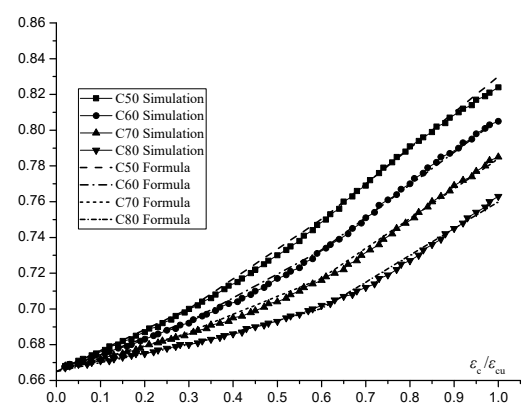

(b) Comparison of the calculation results of $\beta_{1}$ and the numerical fitting results

Fig.5. Comparison of the calculation results of the equivalent coefficient formula and the numerical fitting results

4 Calculation method of the section force of reinforced concrete beam under non-limit state 


\subsection{Force analysis of normal section under bending moment}

Under the action of bending moment, the section strain and stress distribution of reinforced concrete beam in the non-limiting state are shown in Fig.6. The cross-section balance equations are shown in equation (9) and equation (10)

$$
\begin{gathered}
\alpha_{1} \beta_{1} f_{\mathrm{c}} b x_{\mathrm{n}}+f_{\mathrm{s}}^{\prime} A_{\mathrm{s}}^{\prime}=f_{\mathrm{s}} A_{\mathrm{s}} \\
M=f_{\mathrm{s}} A_{\mathrm{s}}\left(h_{0}-\beta_{1} x_{\mathrm{n}} / 2\right)+f_{\mathrm{s}}^{\prime} A_{\mathrm{s}}^{\prime}\left(\beta_{1} x_{\mathrm{n}} / 2-a_{0}^{\prime}\right)
\end{gathered}
$$

Where : $x_{\mathrm{n}}=\frac{\varepsilon_{\mathrm{c}}}{\varepsilon_{\mathrm{c}}+\varepsilon_{\mathrm{s}}} h_{0} ; f_{\mathrm{s}}^{\prime}=E_{\mathrm{s}}^{\prime} \varepsilon_{\mathrm{s}}^{\prime} \leq f_{\mathrm{y}}^{\prime} ; f_{\mathrm{s}}=E_{\mathrm{s}} \varepsilon_{\mathrm{s}} \leq f_{\mathrm{y}}$;

$$
\varepsilon_{\mathrm{s}}^{\prime}=\frac{x_{\mathrm{n}}-a_{0}^{\prime}}{x_{\mathrm{n}}} \varepsilon_{\mathrm{c}}=\frac{h_{0}-a_{0}^{\prime}}{h_{0}} \varepsilon_{\mathrm{c}}-\frac{a_{0}^{\prime}}{h_{0}} \varepsilon_{\mathrm{s}} \text { 。 }
$$

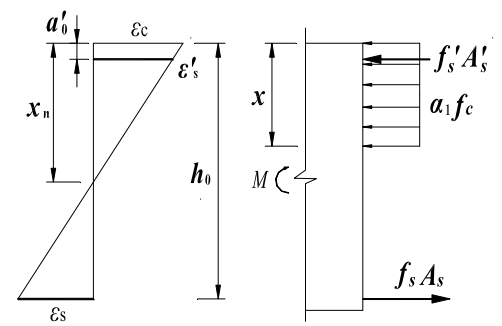

(a) Sectional strain (b) Equivalent section stress

Fig. 6. Normal section strain and stress distribution in nonlimiting state

Depending on whether the tensile and the compressed steel bars yield. Equation (9) can be further expressed as the following four forms:

1) Both the tensile steel bar and the compressed steel bar yielded:

$$
\left(\xi_{1}+\xi_{2} \frac{\varepsilon_{\mathrm{c}}}{\varepsilon_{\mathrm{cu}}}\right) \frac{\varepsilon_{\mathrm{c}}}{\varepsilon_{\mathrm{c}}+\varepsilon_{\mathrm{s}}} f_{\mathrm{c}} b h_{0}+f_{\mathrm{y}}^{\prime} A_{\mathrm{s}}^{\prime}=f_{\mathrm{y}} A_{\mathrm{s}}
$$

2) Yielded of the tensile steel bar and unyield of the compressed steel bar:

$$
\begin{aligned}
& \left(\xi_{1}+\xi_{2} \frac{\varepsilon_{\mathrm{c}}}{\varepsilon_{\mathrm{cu}}}\right) \frac{\varepsilon_{\mathrm{c}}}{\varepsilon_{\mathrm{c}}+\varepsilon_{\mathrm{s}}} f_{\mathrm{c}} b h_{0}+ \\
& E_{\mathrm{s}}^{\prime}\left(\frac{h_{0}-a_{0}^{\prime}}{h_{0}} \varepsilon_{\mathrm{c}}-\frac{a_{0}^{\prime}}{h_{0}} \varepsilon_{\mathrm{s}}\right) A_{\mathrm{s}}^{\prime}=f_{\mathrm{y}} A_{\mathrm{s}}
\end{aligned}
$$

3) Unyielded of the tensile steel bar and yielded of the compressed steel bar:

$$
\left(\xi_{1}+\xi_{2} \frac{\varepsilon_{\mathrm{c}}}{\varepsilon_{\mathrm{cu}}}\right) \frac{\varepsilon_{\mathrm{c}}}{\varepsilon_{\mathrm{c}}+\varepsilon_{\mathrm{s}}} f_{\mathrm{c}} b h_{0}+f_{\mathrm{y}}^{\prime} A_{\mathrm{s}}^{\prime}=E_{\mathrm{s}} \varepsilon_{\mathrm{s}} A_{\mathrm{s}}
$$

4) Neither the tensile steel bar nor the compressed steel bar yielded:

$$
\begin{aligned}
& \left(\xi_{1}+\xi_{2} \frac{\varepsilon_{\mathrm{c}}}{\varepsilon_{\mathrm{cu}}}\right) \frac{\varepsilon_{\mathrm{c}}}{\varepsilon_{\mathrm{c}}+\varepsilon_{\mathrm{s}}} f_{\mathrm{c}} b h_{0}+ \\
& E_{\mathrm{s}}^{\prime}\left(\frac{h_{0}-a_{0}^{\prime}}{h_{0}} \varepsilon_{\mathrm{c}}-\frac{a_{0}^{\prime}}{h_{0}} \varepsilon_{\mathrm{s}}\right) A_{\mathrm{s}}^{\prime}=E_{\mathrm{s}} \varepsilon_{\mathrm{s}} A_{\mathrm{s}}
\end{aligned}
$$

The basic unknowns in the above equations are the concrete edge compressive strain $\varepsilon_{\mathrm{c}}$ and the steel bar tensile strain $\varepsilon_{\mathrm{s}}$. Equations (11) (14) are organized into the following equation:

$$
A \varepsilon_{\mathrm{c}}^{2}+B \varepsilon_{\mathrm{c}}+C=0
$$

The coefficients in the equation are shown in Table 2. Then the $\varepsilon_{\mathrm{c}}$ solution is:

$$
\varepsilon_{\mathrm{c}}=\frac{-B+\sqrt{B^{2}-4 A C}}{2 A}
$$

The bending moments of reinforced concrete beams in non-limit state can be calculated by equation (17):

$$
\begin{gathered}
M=E_{\mathrm{s}} \varepsilon_{\mathrm{s}} A_{\mathrm{s}}\left[h_{0}-\left(\eta_{1}+\eta_{2} \frac{\varepsilon_{\mathrm{c}}}{\varepsilon_{\mathrm{cu}}}\right) \cdot \frac{\varepsilon_{\mathrm{c}}}{\varepsilon_{\mathrm{c}}+\varepsilon_{\mathrm{s}}} \cdot \frac{h_{0}}{2}\right]+ \\
E_{\mathrm{s}}^{\prime} \varepsilon_{\mathrm{s}}^{\prime} A_{\mathrm{s}}^{\prime}\left[\left(\eta_{1}+\eta_{2} \frac{\varepsilon_{\mathrm{c}}}{\varepsilon_{\mathrm{cu}}}\right) \cdot \frac{\varepsilon_{\mathrm{c}}}{\varepsilon_{\mathrm{c}}+\varepsilon_{\mathrm{s}}} \cdot \frac{h_{0}}{2}-a_{0}^{\prime}\right] \\
\left(\varepsilon_{\mathrm{s}} \leq f_{\mathrm{y}} / E_{\mathrm{s}}, \varepsilon_{\mathrm{s}}^{\prime} \leq f_{\mathrm{y}}^{\prime} / E_{\mathrm{s}}^{\prime}\right)
\end{gathered}
$$

Table 2. Concrete strain calculation coefficien

\begin{tabular}{|c|c|c|c|c|}
\hline \multicolumn{2}{|c|}{ Yield state of reinforcement } & $\boldsymbol{A}$ & $\boldsymbol{B}$ & $\boldsymbol{C}$ \\
\hline I & $\begin{array}{c}\text { Tension reinforcement: yield } \\
\text { Compression reinforcement: yield }\end{array}$ & $\frac{\xi_{2} f_{\mathrm{c}} b h_{0}}{\varepsilon_{\mathrm{cu}}}$ & $\xi_{1} f_{\mathrm{c}} b h_{0}+f_{\mathrm{y}}^{\prime} A_{\mathrm{s}}^{\prime}-f_{\mathrm{y}} A_{\mathrm{s}}$ & $\left(f_{\mathrm{y}}^{\prime} A_{\mathrm{s}}^{\prime}-f_{\mathrm{y}} A_{\mathrm{s}}\right) \varepsilon_{\mathrm{s}}$ \\
\hline II & $\begin{array}{c}\text { Tension reinforcement: yield } \\
\text { Compression reinforcement: unyielding }\end{array}$ & $\frac{\xi_{2} f_{\mathrm{c}} b h_{0}}{\varepsilon_{\mathrm{cu}}}+E_{\mathrm{s}}^{\prime} A_{\mathrm{s}}^{\prime} \frac{h_{0}-a_{0}^{\prime}}{h_{0}}$ & $\xi_{1} f_{\mathrm{c}} b h_{0}+E_{\mathrm{s}}^{\prime} A_{\mathrm{s}}^{\prime} \frac{h_{0}-2 a_{0}^{\prime}}{h_{0}} \varepsilon_{\mathrm{s}}-f_{\mathrm{y}} A_{\mathrm{s}}$ & $-\left(f_{\mathrm{y}} A_{\mathrm{s}}+E_{\mathrm{s}}^{\prime} A_{\mathrm{s}}^{\prime} \frac{a_{0}^{\prime}}{h_{0}} \varepsilon_{\mathrm{s}}\right) \mathcal{E}_{\mathrm{s}}$ \\
\hline III & $\begin{array}{c}\text { Tension reinforcement: unyielding } \\
\text { Compression reinforcement: yield }\end{array}$ & $\frac{\xi_{2} f_{\mathrm{c}} b h_{0}}{\varepsilon_{\mathrm{cu}}}$ & $\xi_{\mathrm{l}} f_{\mathrm{c}} b h_{0}+f_{\mathrm{y}}^{\prime} A_{\mathrm{s}}^{\prime}-E_{\mathrm{s}} \varepsilon_{\mathrm{s}} A_{\mathrm{s}}$ & $\left(f_{\mathrm{y}}^{\prime} A_{\mathrm{s}}^{\prime}-E_{\mathrm{s}} \varepsilon_{\mathrm{s}} A_{\mathrm{s}}\right) \varepsilon_{\mathrm{s}}$ \\
\hline IV & $\begin{array}{c}\text { Tension reinforcement: unyielding } \\
\text { Compression reinforcement: unyielding }\end{array}$ & $\frac{\xi_{2} f_{\mathrm{c}} b h_{0}}{\varepsilon_{\mathrm{cu}}}+E_{\mathrm{s}}^{\prime} A_{\mathrm{s}}^{\prime} \frac{h_{0}-a_{0}^{\prime}}{h_{0}}$ & $\xi_{1} f_{\mathrm{c}} b h_{0}+E_{\mathrm{s}}^{\prime} A_{\mathrm{s}}^{\prime} \frac{h_{0}-2 a_{0}^{\prime}}{h_{0}} \varepsilon_{\mathrm{s}}-E_{\mathrm{s}} \varepsilon_{\mathrm{s}} A_{\mathrm{s}}$ & $-\left(E_{\mathrm{s}} \varepsilon_{\mathrm{s}} A_{\mathrm{s}}+E_{\mathrm{s}}^{\prime} A_{\mathrm{s}}^{\prime} \frac{a_{0}^{\prime}}{h_{0}} \varepsilon_{\mathrm{s}}\right) \varepsilon_{\mathrm{s}}$ \\
\hline
\end{tabular}

\subsection{Analysis of the ultimate bearing capacity when the tensile strain of the steel bar controls}

In the calculation of the normal section bearing capacity of the flexural members of the "Code for design of concrete structures", the ultimate tensile strain of tensile steel bars is taken as $\varepsilon_{\mathrm{su}}=0.01{ }^{[1]}$ as a limiting condition. When this happens, the ultimate load capacity should be calculated with the tensile strain of the steel bar reaching $\varepsilon_{\text {su }}$ as the limit state. The calculation method is as follows :
1) The tensile steel bar must yield and its strain was taken as a constant $\varepsilon_{\mathrm{s}}=\varepsilon_{\mathrm{su}}=0.01$.

2) If there is a compressed steel bar, first calculating the yield of the compressed steel bar; if $A_{\mathrm{s}}^{\prime}=0$.

3 ) It is assumed that the strain level of the concrete edge compressive strain is stage II, according to Table 1 and Table $2, \varepsilon_{\mathrm{c}}$ can be calculated by equation(16).

4) Checking whether the calculated strain level of the concrete satisfies the original hypothesis (stage II), if not, select a new strain level (stage I or III) and recalculate. 
5) If there is a compressed steel bar, the strain and stress of the compressed steel bar were obtained and checking, whether the compressed steel bar was yielded. If the compressed steel bar yield, recalculating it according to the unyielding condition.

6) Calculating the ultimate load-bearing capacity of the steel bar under the control of tensile strain according to equation (17).

\section{Calculation examples of reinforced concrete beam}

A reinforced concrete beam, $b \times h=250 \times 600 \mathrm{~mm}, \mathrm{C} 30$ concrete, HRB400 steel bar with $3 \$ 20$ at the bottom of the beam, HRB400 steel bar with $2 \Phi 14$ at the top of the beam, the distance from the center of the steel bar to the edge of the concrete, $a_{\mathrm{s}}=a_{\mathrm{s}}^{\prime}=35 \mathrm{~mm}, h_{0}=565 \mathrm{~mm}$, the bending moment under normal use is $M_{0}=140 \mathrm{kN} \cdot \mathrm{m}$.

\subsection{Limit state analysis of beams}

The bending limit state of the beam was analyzed by numerical integration method and formula calculation method. The calculation results are shown in Table 3.

When the strain of the edge of the concrete compression zone reaches 0.0033 , the strain of the tensile steel bar was about 0.02 , which exceeded the limit of the ultimate tensile strain of 0.01.Therefore, the ultimate state of the beam should be controlled by the ultimate tensile strain of the steel bar.

Table 3. Results of limit state analysis of beams

\begin{tabular}{|c|c|c|c|c|}
\hline \multirow{2}{*}{$\begin{array}{l}\text { Content of } \\
\text { calculation }\end{array}$} & \multicolumn{2}{|c|}{$\begin{array}{l}\text { Controlled by the } \\
\text { ultimate compressive } \\
\text { strain of concrete }\end{array}$} & \multicolumn{2}{|c|}{$\begin{array}{l}\text { Controlled by the } \\
\text { ultimate tensile strain of } \\
\text { reinforcement }\end{array}$} \\
\hline & $\begin{array}{l}\text { Numerical } \\
\text { integraton } \\
\text { calculation }\end{array}$ & $\begin{array}{l}\text { Standard } \\
\text { formula } \\
\text { calculation }\end{array}$ & $\begin{array}{l}\text { Numerical } \\
\text { integration } \\
\text { calculation }\end{array}$ & $\begin{array}{l}\text { Formula } \\
\text { calculation } \\
\text { in this } \\
\text { paper }\end{array}$ \\
\hline $\begin{array}{l}\text { Strain of } \\
\text { concrete } \\
\text { edge } \varepsilon_{\mathrm{c}}\end{array}$ & 0.00330 & 0.00330 & 0.00218 & 0.00219 \\
\hline $\begin{array}{c}\text { Strain of } \\
\text { compressed } \\
\text { steel bar } \varepsilon_{\mathrm{s}}^{\prime}\end{array}$ & 0.00186 & 0.00185 & 0.00143 & 0.00144 \\
\hline $\begin{array}{l}\text { Strain of } \\
\text { tensile steel } \\
\text { bar } \varepsilon_{\mathrm{s}}\end{array}$ & 0.01998 & 0.02000 & 0.01000 & 0.01000 \\
\hline $\begin{array}{c}\text { Height of } \\
\text { actual } \\
\text { pressure area } \\
x_{\mathrm{c}} / \mathrm{mm} \\
\end{array}$ & 80.1 & 79.9 & 101.2 & 101.6 \\
\hline $\begin{array}{l}\text { Ultimate } \\
\text { bearing } \\
\text { capacity } \\
M_{\mathrm{u}} / \mathrm{kN} \cdot \mathrm{m}\end{array}$ & 180.3 & 179.8 & 178.9 & 178.5 \\
\hline
\end{tabular}

It can be seen from the comparison in Table 3:

The calculation results of the formula were in good agreement with the numerical integration results; the bending bearing capacity of the beam in this example should be controlled by the ultimate tensile strain of the steel bar. However, from the calculation results of the ultimate bearing capacity, the difference between the two was small; but from the perspective of the strain distribution in the section, the result was significantly different.

\section{Conclusions}

In this paper, the bending and deformation resistance of reinforced concrete beams under non-limit state were studied, and the following conclusions were obtained:

1) Through numerical analysis, it can be obtained that as the concrete edge $\varepsilon_{\mathrm{c}} / \varepsilon_{\mathrm{cu}}$ increased, the product of the equivalent coefficient $\alpha_{1} \beta_{1}$ was approximately in the form of a convex parabola. The values of the equivalent coefficients $\alpha_{1} \beta_{1}$ and $\beta_{1}$ both decreased, but the change trends were consistent. The calculation result of the linear fitting equation tends to be consistent with the numerical simulation result. The accuracy of the fitting is ideal.

2) Depending on whether the tensile and compressed steel bars were yielded, four forms of calculation expressions and simplified equations were obtained, which can be used to analyze and solve the stress state and bearing capacity of the reinforced concrete beam in the non-limit state.

3) Through the analysis of a typical non-limiting case and calculation cases, it is shown that the method and equations of section strain analysis and stress calculation of reinforced concrete beams in this paper under nonlimit state are feasible, and the accuracy is also ideal.

\section{References}

1. GB50010-2010.Code for design of concrete structures[S].Beijing: China Building Industry Press, (2010).

2. S.m Liu,M Sun, Q.y Liu. Study on bearing capacity of beams strengthened with section en-largement method considering secondary loading process[J].Advanced Materials Research,(2012), 368-373:2200-2203

3. B Xing, X.z Li, S.z Kang. Effect of initial stress state on mechanical properties of reinforced concrete beams[J].Bridge Construction,(2014),44 (5):81-87

4. C.x Li, Z.s Ding, S.l Yan. Experimental study on hysteresis strain of reinforced concrete beams [j].Journal of Wuhan University of Technology, (2012), (8): 103-106

5. S.m Liu, Q.y Liu. Bearing capacity of beams strengthened by common methods considering strain lag effect $[j]$. Applied Mechanics and Materials, (2012), 166-169: 1789-1792.

6. S.r Luo,W.d Wu,W Chen. Study. on the bending behavior of $R C$ beams strengthened with selfcompacting concrete under secondary stress[J]. Engineering Mechanics, (2015), 32(4):62-68.

7. B Yang, G.f An, C.I Shan. Calculation method of normal section bearing capacity of reinforced bending member[J].Journal of Highway and Transportation, (2015), 32(6): 81-88 . 